\title{
Peritrophic membrane structure of Aedes aegypti (Diptera: Culicidae) mosquitoes after infection with dengue virus type 2 (D2-16681)
}

\author{
Supattra SuWANMANeE, ${ }^{1, \dagger}$ Urai Chaisri, ${ }^{1}$ Ladawan WASINPIYAMONGKOL ${ }^{2}$ and \\ Natthanej LUPLERTLOP ${ }^{2, *}$ \\ ${ }^{1}$ Department of Tropical Pathology, and ${ }^{2}$ Tropical Hygiene, Faculty of Tropical Medicine, Mahidol University; Bangkok 10400, \\ Thailand
}

(Received 24 September 2008; Accepted 3 December 2008)

\begin{abstract}
The peritrophic membrane (PM) is a non-cellular tissue involved in the protection of midgut epithelium from mechanical damage and insults from pathogens. This study was carried out to determine the involvement of PM in mosquitoes after infection with dengue virus. Aedes aegypti (Diptera: Culicidae) mosquitoes were fed sucrose and human blood with and without dengue virus type 2 (D2-16681), and collected at $0.5,1,6$, and $12 \mathrm{~h}$, respectively. Specimens were prepared for examination under light and electron microscopy. The results showed that PM was produced only in the blood-fed mosquitoes. The infected blood meal induced the mosquitoes to produce PM in their midgut earlier and thicker than in mosquitoes with blood alone. The initial evidence of PM occurred at $1 \mathrm{~h}$ post-blood meal (PBM) as a matrix-like structure. By $6 \mathrm{~h}$ PBM, PM had become a layer, which persisted at $12 \mathrm{~h}$. Among mosquitoes fed with blood alone, this structure was found only from 6 and $12 \mathrm{~h}$ PBM. Dengue virus type 2 induced different modifications of mosquito PM construction and structures, confirmed under an electron microscope.
\end{abstract}

Key words: Flaviviridae; peritrophic matrix; ultrastructure

\section{INTRODUCTION}

Dengue virus is one of the most important resurging mosquito-borne diseases belonging to the Flaviviridae family of small enveloped viruses. It carries a single-stranded RNA virus, divided into four serotypes: DEN1, DEN2, DEN3, and DEN4. Dengue virus infection is prevalent in tropical areas of over 100 countries, with 2.5 billion people at risk of acquiring the infection. Fifty million estimated infections and 500,000 dengue hemorrhagic fever (DHF) cases occur annually (Gubler, 2002). Dengue infection is caused by the ingestion of viremic blood containing the virus by Aedes mosquitoes followed by passage to a second human host. Aedes aegypti (Diptera: Culicidae) is the most important vector for dengue transmission, which is initiated when the female mosquito ingests an infective blood meal (Gubler, 2002). The midgut of a mosquito is the first site of interaction between the mosquito and pathogen and plays an important role in vector competence (Beerntsen et al., 2000). Midgut epithelial cells produce the peritrophic membrane, sometimes called the peritrophic matrix (PM), a non-cellular material that separates the midgut lumen containing the ingested food from the midgut epithelium (Jacobs-Lorena and Oo, 1996; Tellam et al., 1999; Ibrahim et al., 2000; Shao et al., 2001). The PM is composed of chitin, proteins, and proteoglycans (Wang and Granados, 2001) divided into two types: Type I PM is found in adult hematophagous insects and forms a thick bag-like structure that completely surrounds the ingested blood meal. Type II PM is produced in larval and adult (except hematophagous) insects, forms a thin open-ended tube-like structure and is produced in a specialized region located at the junction between the foregut and midgut called the

\footnotetext{
* To whom correspondence should be addressed at: E-mail: tmnll@mahidol.ac.th

$\dagger$ Present address: Department of Tropical Pathology, Faculty of Tropical Medicine, Mahidol University, 420/6 Ratchawithi Road, Ratchadewee, Bangkok 10400, Thailand.

DOI: 10.1303/aez.2009.257
} 
cardia (Jacobs-Lorena and Oo, 1996; Tellam et al., 1999). Functions of the PM include protecting the midgut epithelium from mechanical damage, acting as a lubricant helping food pass through the gut, and preventing swelling and rupture of the midgut after the ingestion of high molecularweight foods exerting high osmotic pressure. PM serves as a barrier against the entry of pathogens and toxins, prevents the rapid excretion of digestive enzymes and also limits the rate of food digestion. Moreover, it plays a role in the prevention of nonspecific binding of undigested materials to midgut microvilli surfaces or binding to transport proteins at the midgut surface (Zhuzhikov, 1964; Terra, 1990; Lehane, 1997; Villalon et al., 2003). In addition, it helps in heme detoxification (Pascoa et al., 2002), and the assimilation and elimination of toxic ammonium ions (Kato et al., 2002). Dengue virus can invade and replicate in the midgut epithelium of Ae. aegypti mosquitoes. The morphology of the PM may change after the mosquitoes receive an insult from this virus.

The role of PM formation in dengue invasion of the midgut has not been examined; therefore, the purpose of this study was to examine the involvement of PM in midgut of Ae. aegypti mosquitoes after infection with dengue virus type 2 (D216681) at different time points.

\section{MATERIALS AND METHODS}

Rearing mosquitoes. Ae. aegypti mosquitoes (white-eyed Liverpool strain) were maintained in an insectary in the Department of Medical Entomology (Faculty of Tropical Medicine, Mahidol University, Bangkok, Thailand). Eggs were hatched and transferred to the rear of a plastic tray which was half-filled with well water and artificial food. After hatching from the pupa, the adults were maintained at $27^{\circ} \mathrm{C}$ with $80 \%$ relative humidity under a $14: 10 \mathrm{~h}$ light/dark cycle. Adult mosquitoes were offered $10 \%$ sucrose. Three- to four-day-old female mosquitoes were collected for the experiment.

Virus propagation. Dengue virus type 2 strain (D2-16681) was obtained from the Armed Forces Research Institute of Medical Sciences (AFRIMS) (Bangkok, Thailand). The virus had been routinely passaged in $\mathrm{C} 6 / 36$ cells culture performed in a $25 \mathrm{~cm}^{2}$ culture flask (Corning, USA). After adsorp- tion for $90 \mathrm{~min}, 5 \mathrm{ml}$ MEM medium (Gibco, USA) containing 10\% fetal bovine serum (FBS) (Gibco) and $1 \%$ penicillin-streptomycin was added. The culture flask was incubated at $28^{\circ} \mathrm{C}$ in a $5 \% \mathrm{CO}_{2}$ incubator. Aliquots of the culture medium were harvested seven days after infection and stored at $-80^{\circ} \mathrm{C}$ until plaque titration and mosquito inoculation.

Viral plaque assay. LLC-MK2 cells were seeded in six-well cell culture plates (Corning) at a density of $5.0 \times 10^{5}$ cells/well and were incubated for three to four days at $37^{\circ} \mathrm{C}$ in $5 \% \mathrm{CO}_{2}$ to produce a confluent monolayer. Cell monolayers were inoculated with 10-fold serial dilutions of virus in a final volume of $0.2 \mathrm{ml}$. Viral adsorption (from extracted samples: negative media alone, sucrose, infected mosquito and infective blood meal) was allowed to proceed for $90 \mathrm{~min}$ at $37^{\circ} \mathrm{C}$ with plate rocking every $15 \mathrm{~min}$. A $3 \mathrm{ml}$ overlay of MEM, 5\% FBS, and $0.6 \%$ SEQEM agar was added at the conclusion of adsorption. The infected monolayers were incubated at $37^{\circ} \mathrm{C}$ in $5 \% \mathrm{CO}_{2}$. Seven days after infection, a second overlay, similar to the first but with the addition of $1.5 \%$ neutral red (SigmaAldrich, UK), was added to the wells, and the plates were incubated at $37^{\circ} \mathrm{C}$ in $5 \% \mathrm{CO}_{2}$ overnight. The plaques were counted, and the viral titer was calculated and expressed as $\mathrm{pfu} / \mathrm{ml}$.

Infection of mosquitoes and verification of dengue infection. Insectary-maintained $A e$. aegypti mosquitoes were infected by oral feeding with dengue virus type 2 (D2-16681) at $10^{6} \mathrm{pfu} / \mathrm{ml}$. Mosquitoes were maintained at $28^{\circ} \mathrm{C}$ and 70 to $80 \%$ relative humidity. Pools consisting of five mosquitoes were removed at different time points, $0.5,1,6,12 \mathrm{~h}$ post-infection, and frozen for RTPCR analysis. Dengue virus in mosquitoes was detected by RT-PCR and serotype-specific primers by nested-PCR.

RNA extraction. Total RNA was extracted with a QIAmp viral RNA kit (QIAGEN, USA), according to the manufacturer's suggested protocol. RNA was eluted twice in $40 \mu 1$ nuclease free water. The extracted solution was stored at $-70^{\circ} \mathrm{C}$ until evaluated.

Nested RT-PCR assay. Nested RT-PCR of dengue virus RNA was carried out with dengue virus consensus and serotype-specific primers, as described previously (Lanciotti et al., 1992). Modifications to the procedure were as follows: $5 \mu 1$ of 
RNA in $50 \mu 1$ reaction volume was used with the QIAGEN OneStep RT-PCR kit (QIAGEN). RTPCR was carried out according to the manufacturer's instructions with $55^{\circ} \mathrm{C}$ annealing temperature. The resultant PCR product was diluted to $1: 500$ in water. Nested-PCR was carried out with $5 \mu \mathrm{l}$ of the diluted RT-PCR product in $50 \mu \mathrm{l}$ reaction volume with the TaqPCR Master Mix kit (QIAGEN). Initial denaturation of $10 \mathrm{~min}$ at $94^{\circ} \mathrm{C}$ was followed by 25 cycles, each consisting of $94^{\circ} \mathrm{C}$ for $30 \mathrm{~s}, 50^{\circ} \mathrm{C}$ for $30 \mathrm{~s}$, and $72^{\circ} \mathrm{C}$ for $45 \mathrm{~s}$, followed by a final extension step of $72^{\circ} \mathrm{C}$ for $10 \mathrm{~min}$. Both the RT-PCR and nested-PCR products were analyzed by gel electrophoresis on $2 \%$ agarose gel containing ethidium bromide $(0.5 \mu \mathrm{g} / \mathrm{ml})$. A band on the agarose gel of the correct size was visualized by the Bioimaging system (Syn-Gene, UK).

Mosquito preparation. One hundred and eighty female mosquitoes were starved for two days prior to feeding. Twenty starving mosquitoes were collected as a control group. One hundred and sixty mosquitoes divided into groups 1, 2 and 3 were fed with $10 \%$ sucrose and human blood without and with dengue virus type 2 (D2-16681), respectively. The infective blood meal was prepared by mixing $10^{6} \mathrm{pfu} / \mathrm{ml}$ of virus, pack cells of washed human erythrocytes, and $10 \%$ sucrose ( $4: 1: 1$ ratio). This suspension was placed on non-wettable fine nylon mesh covering a small carton of mosquitoes for them to imbibe for $30 \mathrm{~min}$. Fully engorged mosquitoes in each group were collected at $0.5,1,6$, and $12 \mathrm{~h}$ (10 mosquitoes per time point) after feeding, and then anesthetized at $-70^{\circ} \mathrm{C}$. The legs and wings were removed before fixing in $2.5 \%$ glutaraldehyde in $0.1 \mathrm{M}$ cacodylate buffer containing $5 \%$ sucrose, at $\mathrm{pH} 7.4,4^{\circ} \mathrm{C}$ for $24 \mathrm{~h}$. Finally, all specimens were prepared and examined by light and transmission electron microscopy.

Preparation for light microscopy. The fixed specimens of starved and human blood fed mosquitoes were dehydrated through a graded series of ethanol and embedded in paraffin. Five-micrometer-thick serial sections were cut and placed on glass slides, stained with Periodic Acid Schiff (PAS) (Luna, 1968) and examined under a Nikon Eclipse E600 light microscope.

Preparation for electron microscopy. After pre-fixation, the specimens were post-fixed in $2 \%$ $\mathrm{OsO}_{4}$ in $0.1 \mathrm{M}$ cacodylate buffer for $1 \mathrm{~h}$, dehydrated by ethanol and embedded in Epon 812 (Electron
Microscopy Sciences, USA). Transverse sections of semithin ( $1 \mu \mathrm{m}$ thick) were cut by an ultramicrotome, placed on a glass slide, stained with $1 \%$ toluidine blue, and examined under a light microscope to study the entire tissue. When the area of interest was located, ultrathin sections were cut, picked up and placed on copper grids. They were then stained with uranyl acetate and lead citrate before examination under a transmission electron microscope (Hitachi, model H-7000, Japan) at $75 \mathrm{kV}$.

Statistical analysis. PM thickness and the size of midgut epithelial cells (in the anterior region of the midgut) were accurately measured from micrographs using the Image Frame Work program. The results are presented as the mean \pm standard deviation (SD).

\section{RESULTS}

The present study showed that PM formation in the Ae. aegypti midgut after the infective blood meal with dengue virus type 2 significantly differed from in blood alone, sucrose, and starving groups, as described below.

Virus growth kinetics was determined in all samples by plaque titration performed in a confluent monolayer of LLC-MK2 cells as previously described (Miller and Mitchell, 1986; Huang et al., 2000). Only two groups, infective blood meal and infected mosquito, showed plaque titration at $10^{6}$ and $10^{7} \mathrm{pfu} / \mathrm{ml}$, respectively.

We confirmed the specific dengue virus by RTPCR and nested-PCR, as described previously (Lanciotti et al., 1992; Chien et al., 2006; Gomes et al., 2007). After amplification, $5 \mu$ of each product was analyzed by agarose gel electrophoresis utilizing $2 \%$ agarose gel, and the serotype was determined. The amplicon was approximately $119 \mathrm{bp}$, specific for dengue virus type 2 as described by Chien et al. (2006) (Fig. 1).

There was no PM in the starved (control) Ae. aegypti midgut when observed under light and electron microscopy. This result was the same as in sucrose-fed mosquitoes (group 1), in which PM was not observed in each time interval. The midgut of both groups consisted of a single layer of columnar epithelium lining the lumen (Fig. 2A, B). The apical region of the epithelium was characterized by a striated border of numerous microvilli projecting into the lumen (Fig. 2B, C) (image shown only at 


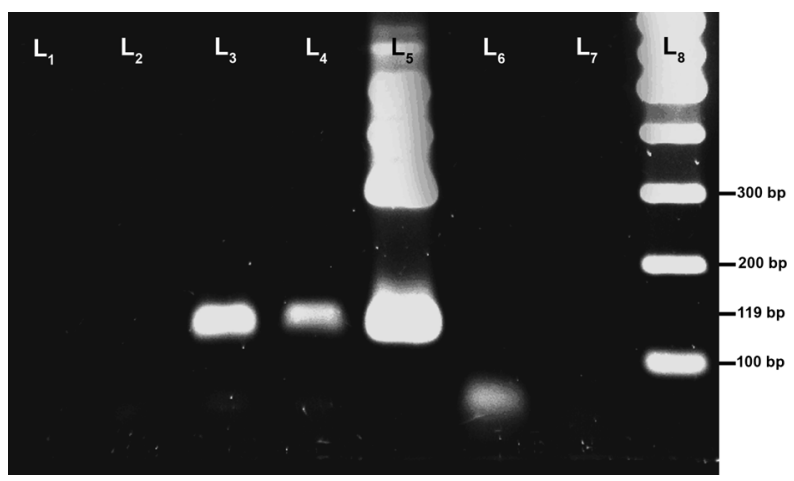

Fig. 1. Agarose gel analysis of the DNA product from RTPCR of RNA samples isolated from infective blood meal and infected Ae. aegypti mosquito. $\mathrm{L}_{1}$, media alone; $\mathrm{L}_{2}$, RNaseDNase free water; $\mathrm{L}_{3}$, infective blood meal; $\mathrm{L}_{4}$, infected mosquito; $\mathrm{L}_{5}$, positive control dengue mix (dengue type $1-4$ ); $\mathrm{L}_{6}$, negative control; $\mathrm{L}_{7}$, sucrose; $\mathrm{L}_{8}$, DNA ladder.

\section{$6 \mathrm{~h}$ after sucrose feeding).}

The results from PAS staining demonstrated that the PM formed only in blood-fed mosquitoes. The structure of PM was revealed as a fine delicate pink color between the epithelium and the food bolus, visible only at 6 and $12 \mathrm{~h}$ post-blood meal (PBM) (picture not shown). These results were confirmed by toluidine blue staining and electron microscopy.

Toluidine blue-stained midguts from human blood-fed mosquitoes (group 2) were observed under a light microscope. PM was not observed at $1 \mathrm{~h} \mathrm{PBM} \mathrm{(Fig.} \mathrm{3A).} \mathrm{Although} \mathrm{a} \mathrm{pale} \mathrm{blue} \mathrm{line} \mathrm{simi-}$ lar to PM was observed between the epithelium and red blood cells, this was thought to be the tips of dense microvilli, demonstrating the first formation of PM at $6 \mathrm{~h}$ PBM which appeared as a pale blue thin layer between the epithelium and the ingested blood, approximately $0.73 \pm 0.28 \mu \mathrm{m}$ in thickness (Fig. 3C). Subsequently (at $12 \mathrm{~h}$, Fig. $3 \mathrm{E})$, there was decrease in PM thickness $(0.42 \pm 0.06 \mu \mathrm{m})$. When examined under an electron microscope, the PM structure at $6 \mathrm{~h}$ (Fig. 4C) was similar to at $12 \mathrm{~h}$ (Fig. 4E), a thin foamy layer.

The PM in the midgut after being fed human blood with dengue virus type 2 (group 3 ) was produced earlier and thicker than in mosquitoes fed blood alone. It first appeared at $1 \mathrm{~h}$ PBM, surrounding the red blood cells as a matrix-like structure and about $7.36 \pm 1.64 \mu \mathrm{m}$ (Figs. 3B and 4B). At $6 \mathrm{~h}$ $\mathrm{PBM}$, a light microscope image showed that the $\mathrm{PM}$ in the midgut had become a thick colorless layer of approximately $4.19 \pm 0.89 \mu \mathrm{m}$ (Fig. 3D)
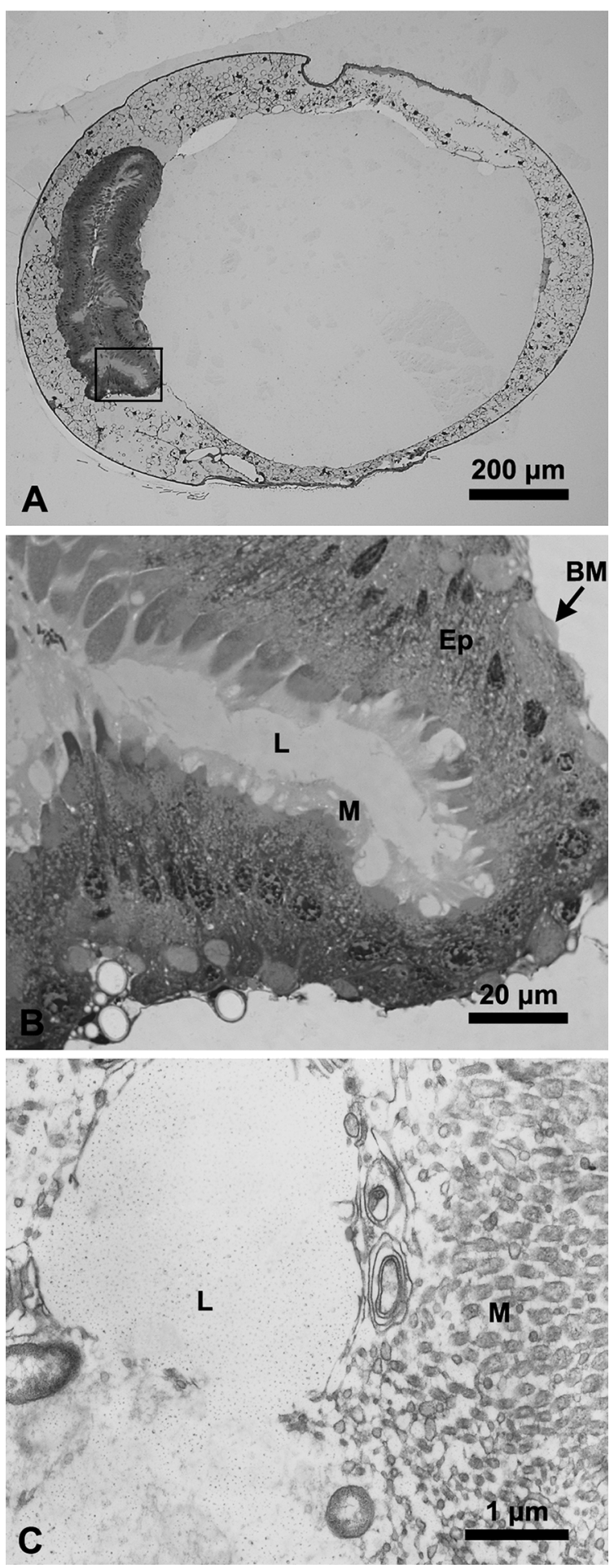

Fig. 2. Sucrose-fed female Ae aegypti midgut at $6 \mathrm{~h}$. (A, B) Transverse section light micrographs of toluidine blue staining, demonstrating a single layer of columnar epithelium (Ep) resting on the basement membrane (BM); high magnification of inset from A shown in B. (C) Transmission electron micrograph, showing numerous microvilli (M) at the apical pole extending into the lumen (L). 


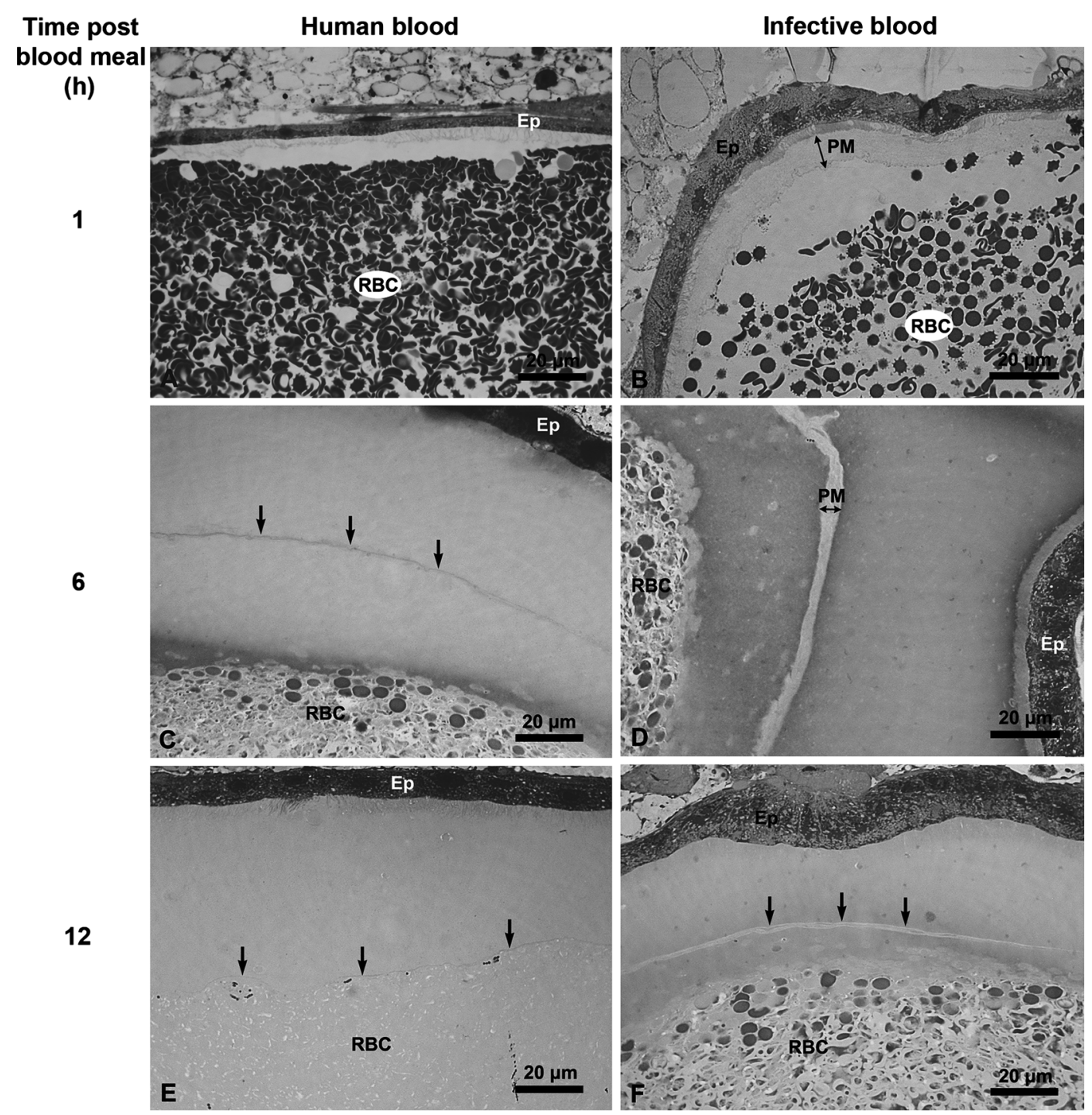

Fig. 3. Light micrographs from toluidine blue staining of adult Ae. aegypti midgut after feeding with human blood and infected blood at different times. (A) PM was not observed. (C) PM can be seen as a pale blue thin layer (arrows). (E) PM was decreased in thickness (arrows). (B) PM was observed as a matrix-like structure. (D) Thick colorless layer of the PM. (F) PM was decreased in thickness (arrows). Epithelium (Ep), red blood cells (RBC).

and the ultrastructure revealed multilayers of the PM in parallel (Fig. 4D). At $12 \mathrm{~h}$ (Figs. 3F and 4F), the general appearance of the PM structure was similar to at $6 \mathrm{~h}$ except that PM thickness had decreased $(1.76 \pm 0.38 \mu \mathrm{m})$.

Before engorgement, the midgut was composed of a single layer of columnar epithelium. After blood ingestion, the morphology of the midgut changed both with blood alone (Fig. 3A, C, E) and infective blood (Fig. 3B, D, F). Marked distension of the midgut provoked flattening of the epithelium to a single layer of cuboidal epithelium. Changes to the morphology of the midgut continued and at $6 \mathrm{~h}$
(Fig. 3C, D) and $12 \mathrm{~h}$ (Fig. 3E, F) PBM, blood digestion was visually evident as the presence of lysed erythrocytes.

The means of PM thickness and the size of midgut epithelial cells of mosquito group 1, 2, 3 and the control are shown in Table 1.

\section{DISCUSSION}

The digestive tract of insects is commonly shielded by the PM, which plays many important roles in protecting against various microbial, chemical, and physical challenges (Terra, 1990; Lehane, 


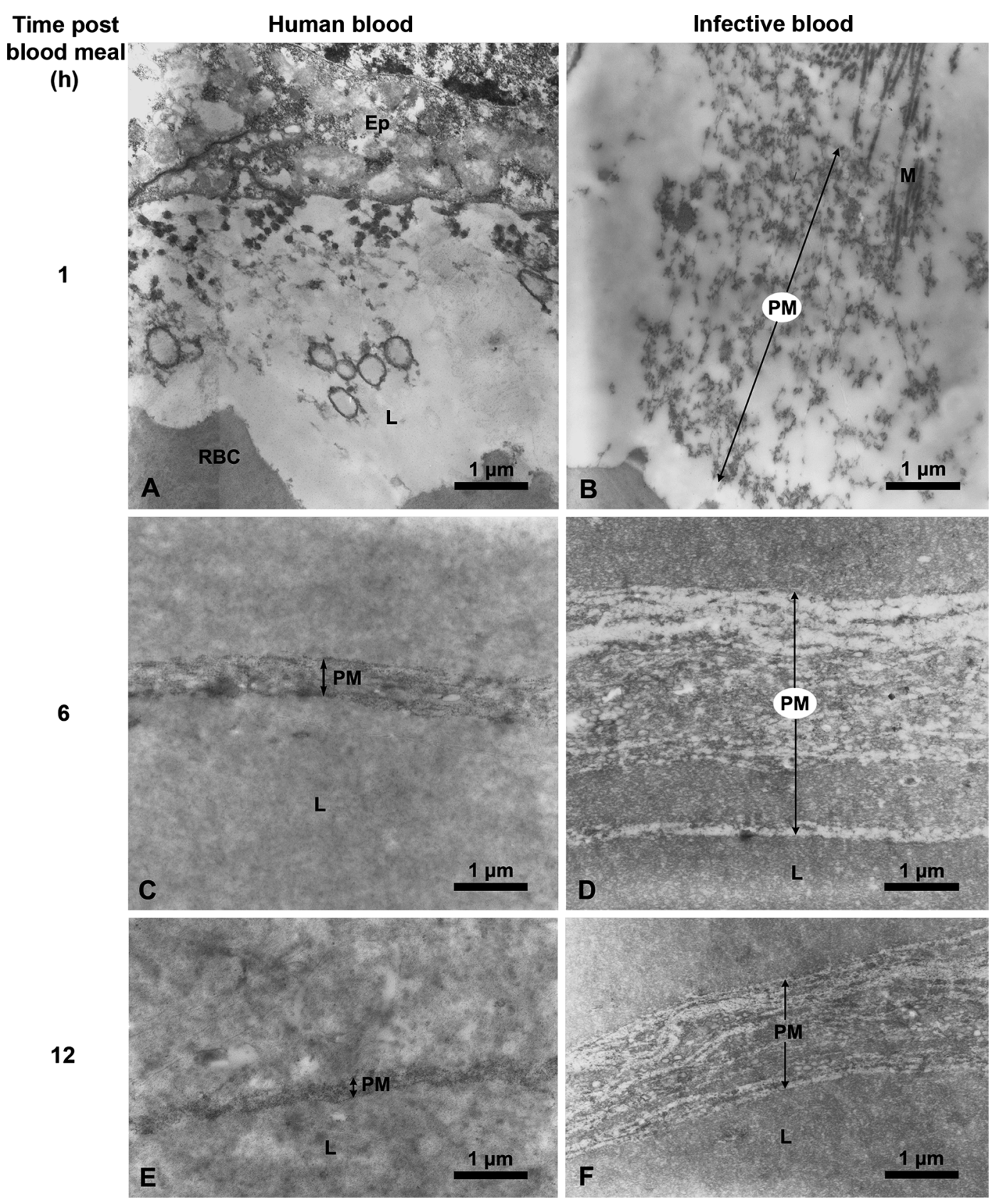

Fig. 4. Electron micrographs of midgut sections from adult Ae. aegypti after feeding with human blood and infected blood at different time points. (A) PM was not found. (C, E) PM was visible as a foamy thin layer. (B) PM was observed as a matrix-like structure. (D, F) Multilayers of PM. Epithelium (Ep), lumen (L), microvilli (M), red blood cells (RBC).

1997). Many species produce different PM types at different life stages. In mosquitoes, type II PM is produced in the larval stage while type I PM is produced only in adult female mosquitoes (Stamm et al., 1978; Tellam, 1996; Tellam et al., 1999).

The present report contributes information to the histology and ultrastructure of PM in the midgut of Ae. aegypti mosquitoes. The PM is produced in di- rect response to blood feeding; in contrast, it is not produced when mosquitoes receive sucrose or are starving, consistent with findings described by Perrone and Spielman (1988), Jacobs-Lorena and Oo (1996), Tellam et al. (1999) and Shao et al. (2001). PM structure is composed of chitin fibers forming a strong and flexible framework to which proteins and proteoglycans attach (Wang and Granados, 
Table 1. Means ( $\pm \mathrm{SD}$ ) of PM thickness and the height of midgut epithelial cells (in the anterior region of midgut) of Ae. aegypti mosquitoes after feeding with sucrose (group 1), human blood (group 2), and human blood with dengue virus type 2 (group 3 )

\begin{tabular}{|c|c|c|c|c|c|}
\hline & $\begin{array}{l}\text { No. of mosquitoes } \\
\text { examined }\end{array}$ & PM & $\begin{array}{l}\text { PM thickness } \\
\qquad(\mu \mathrm{m})\end{array}$ & $\begin{array}{c}\text { Size of midgut } \\
\text { epithelial cells }(\mu \mathrm{m})\end{array}$ & $\begin{array}{l}\text { Shape of midgut } \\
\text { epithelial cells }\end{array}$ \\
\hline Control & 10 & - & - & $75.86 \pm 13.81$ & columnar \\
\hline Group 1 & 10 & - & - & $66.04 \pm 14.01$ & columnar \\
\hline \multicolumn{6}{|l|}{ Group 2} \\
\hline $0.5 \mathrm{~h}$ & 10 & - & - & $11.58 \pm 3.63$ & cuboid \\
\hline $1 \mathrm{~h}$ & 10 & - & - & $9.32 \pm 3.31$ & cuboid \\
\hline $6 \mathrm{~h}$ & 10 & + & $0.73 \pm 0.28$ & $10.68 \pm 3.11$ & cuboid \\
\hline $12 \mathrm{~h}$ & 10 & + & $0.42 \pm 0.06$ & $11.23 \pm 3.24$ & cuboid \\
\hline \multicolumn{6}{|l|}{ Group 3} \\
\hline $0.5 \mathrm{~h}$ & 10 & - & - & $11.67 \pm 3.81$ & cuboid \\
\hline $1 \mathrm{~h}$ & 10 & + & $7.36 \pm 1.64$ & $10.28 \pm 2.70$ & cuboid \\
\hline $6 \mathrm{~h}$ & 10 & + & $4.19 \pm 0.89$ & $13.15 \pm 3.65$ & cuboid \\
\hline $12 \mathrm{~h}$ & 10 & + & $1.76 \pm 0.38$ & $12.78 \pm 3.13$ & cuboid \\
\hline
\end{tabular}

2001). Proteins and chitin play important functional roles and the number of proteins in the PM varies among species (Moskalyk et al., 1996). After a blood meal, protein and chitin synthesis is activated and results in PM formation (Bertram and Bird, 1961; Staubli et al., 1966; Peters, 1992; Morlais and Severson, 2001; Shao et al., 2005). Among female adult Ae. aegypti mosquitoes, PM formation in the midgut was almost completely absent when chitin synthesis was disrupted; PM proteins alone failed to form this structure (Wang and Granados, 2001; Kato et al., 2006). In addition, the inhibition of protein synthesis resulted in disturbed PM formation (Zimmermann and Peters, 1987; Terra, 2001).

In adult Anopheles aquasalis, An. albitarsis, An. bellator, An. homunculus (Chadee and Beier, 1995), An. gambiae, An. stephensi (Freyvogel and Staubli, 1965), An. darlingi (Okuda et al., 2005), the PM developed 18, 30, 30, 36, 13, 32, $18 \mathrm{~h}$ PBM, respectively. Compared to other mosquitoes, such as Culex tarsalis (Freyvogel and Staubli, 1965), Cx. quinquefasciatus (Okuda et al., 2002), and Ae. vigilax (Wijffels et al., 1999), this barrier occurred at 10, 12, and $4 \mathrm{~h}$ PBM, respectively. The PM of adult Culiseta melanura mosquitoes first appeared at $6 \mathrm{~h}$ PBM and reached maximum thickness at $12 \mathrm{~h}$ (Weaver and Scott, 1990). The kinetics of PM formation and degradation were found to be related to the ingestion and time of digestion of the blood meal (Secundino et al., 2005).

In this study, PM formation was first observed 6 $\mathrm{h}$ after feeding Ae. aegypti mosquitoes with blood alone; this finding is in line with previous studies (Freyvogel and Staubli, 1965; Perrone and Spielman, 1988). Interestingly, this barrier was observed as early as $1 \mathrm{~h}$ and was fully formed at $6 \mathrm{~h}$ postblood with dengue virus type 2 (D2-16681) meal, which induced the mosquitoes to produce this structure earlier and thicker than in mosquitoes fed blood alone. This may be a defense mechanism of mosquitoes to protect their midgut from virus. Lehane (1997) reported that the degree of microbial contamination of the liquid diet may be a more important factor determining the presence or absence of the PM in most cases. Insects feeding exclusively on a largely sterile, or at least a less infected liquid diet, tend to lack a PM while those that feed on liquid diets likely to be heavily contaminated with microorganisms tend to retain their PM. Billingsley and Rudin (1992) described that the infectivity of Ae. aegypti by Plasmodium gallinaceum was reduced when PM thickness increased, indicating that the PM does act as a partial barrier to Plasmodium development.

Dengue virus can invade and replicate in the midgut epithelium of Ae. aegypti mosquitoes. How do viruses invade the midgut epithelium of bloodsucking insects after a blood meal? Three strategies include: 1) it may invade before PM formation; 2) 
it may persist in the remnants of the blood meal until the PM dissolves and then attach to the epithelium; 3) it may disrupt and penetrate the PM. Dengue virus may fall into the first category, due to a previous study stating that most arboviruses penetrate the mosquito gut soon after blood meal ingestion and before the PM has formed (Devenport and Jacobs-Lorena, 2005). Litomosoides chagasfilhoi microfilariae can invade the midgut epithelium during PM development of Culex quinquefasciatus, but when the PM was fully formed, microfilariae were no longer able to cross it (Santos et al., 2006). On the other hand, it may belong to the third strategy as Mitsuhashi et al. (2007) demonstrated that fusolin, the constitutive protein of the spindles of entomopoxvirus, may bind with chitin in the PM, thus enhancing disruption in the host insect. In larval Ae. aegypti, the motility caused by Derris urucu extract (used as an insecticide) related to disruption of the PM structure. PM disruption can facilitate the transport and enhance the insecticidal activity of pathogens (Gusmão et al., 2002).

From this study, we can conclude that there are changes in the construction and structure of the $\mathrm{PM}$ in the midgut of Ae. aegypti mosquitoes during the ingestion of blood with dengue virus type 2 . Some compartments or products of this virus may enhance the process of PM production in the midgut of mosquitoes. This event is one of the most important defense mechanisms of mosquitoes to protect their midgut from virus infection; therefore, the relationship of virus molecules and other mosquito innate immune responses related to PM should be explored through further experimentation.

\section{ACKNOWLEDGEMENTS}

This study was supported by a research grant from the Faculty of Tropical Medicine, Mahidol University in 2006. The authors are grateful to Mr. Irwin F. Chavez for his critical reading of this manuscript and Dr. Dorothée Missé for her helpful suggestions.

\section{REFERENCES}

Beerntsen, B. T., A. A. James and B. M. Christensen (2000) Genetics of mosquito vector competence. Microbiol. Mol. Biol. Rev. 64: 115-137.

Bertram, D. S. and R. G. Bird (1961) Studies on mosquitoborne viruses in their vectors 1: the normal fine structure of the midgut epithelium of the adult female Aedes aegypti (L.) and the functional significance of its modifica- tions following a blood meal. Trans. R. Soc. Trop. Med. Hyg. 55: 404-423.

Billingsley, P. F. and W. Rudin (1992) The role of the mosquito peritrophic membrane in bloodmeal digestion and infectivity of Plasmodium species. J. Parasitol. 78: $430-440$

Chadee, D. D. and J. C. Beier (1995) Blood-digestion kinetics of four Anopheles species from Trinidad, West Indies. Ann. Trop. Med. Parasitol. 89: 531-540.

Chien, L. J., T. L. Liao, P. Y. Shu, J. H. Huang, D. J. Gubler and G. J. Chang (2006) Development of real-time reverse transcriptase PCR assays to detect and serotype dengue viruses. J. Clin. Microbiol. 44: 1295-1304.

Devenport, M. and M. Jacobs-Lorena (2005) The peritrophic matrix of hematophagous insects. In Biology of Disease Vectors (W. C. Marquardt, ed.). Elsevier Academic Press, Amsterdam, pp. 297-310.

Freyvogel, T. A. and W. Staubli (1965) The formation of peritrophic membrane in Culicidae. Acta Trop. 22: 118-147.

Gomes, A. L., A. M. Silva, M. T. Cordeiro, G. F. Guimarães, E. T. Jr. Marques and F. G. Abath (2007) Single-tube nested PCR using immobilized internal primers for the identification of dengue virus serotypes. J. Virol. Methods 145: 76-79.

Gubler, D. J. (2002) The global emergence/resurgence of arboviral diseases as public health problems. Arch. Med. Res. 33: 330-342.

Gusmão, D. S., V. Páscoa, L. Mathias, I. J. C. Vieira, R. BrazFilho and F. J. A. Lemos (2002) Derris (Lonchocarpus) итиси (Leguminosae) extract modifies the peritrophic matrix structure of Aedes aegypti (Diptera: Culicidae). Mem. Inst. Oswaldo Cruz. 97: 371-375.

Huang, C. Y., S. Butrapet, D. J. Pierro, G. L. Chang, A. R. Hunt, N. Bhamarapravati, D. J. Glubler and R. M. Kinney (2000) Chimeric dengue type 2 (vaccine strain PDK53)/dengue type 1 virus as a potential candidate dengue type 1 virus vaccine. J. Virol. 74: 3020-3028.

Ibrahim, G. H., C. T. Smartt, L. M. Kiley and B. M. Christensen (2000) Cloning and characterization of a chitin synthase cDNA from the mosquito Aedes aegypti. Insect Biochem. Mol. Biol. 30: 1213-1222.

Jacobs-Lorena, M. and M. M. Oo (1996) The peritrophic matrix of insects. In The Biology of Disease Vectors (B. J. Beaty and W. C. Marquardt, eds.). University Press of Colorado, Colorado, pp. 318-332.

Kato, N., R. Dasgupta, C. Smartt and B. M. Christensen (2002) Glucosamine: fructose-6-phosphate aminotransferase: gene characterization, chitin biosynthesis and peritrophic matrix formation in Aedes aegypti. Insect Mol. Biol. 11: 207-216.

Kato, N., C. R. Mueller, J. F. Fuchs, V. Wessely, Q. Lan and B. M. Christensen (2006) Regulatory mechanisms of chitin biosynthesis and roles of chitin in peritrophic matrix formation in the midgut of adult Aedes aegypti. Insect Biochem. Mol. Biol. 36: 1-9.

Lanciotti, R. S., C. H. Calisher, D. J. Gubler, G. J. Chang and A. V. Vorndam (1992) Rapid detection and typing of dengue viruses from clinical samples by using reverse 
transcriptase-polymerase chain reaction. J. Clin. Microbiol. 30: 545-551.

Lehane, M. J. (1997) Peritrophic matrix structure and function. Annu. Rev. Entomol. 42: 525-550.

Luna, L. G. (1968) Manual of Histologic Staining Methods of the Armed Forces Institute of Pathology. McGrawHill Book Company, New York. 158 pp.

Miller, B. R. and C. J. Mitchell (1986) Passage of yellow fever virus: its effect on infection and transmission rates in Aedes aegypti. Am. J. Trop. Med. Hyg. 35: 1302-1309.

Mitsuhashi, W., H. Kawakita, R. Murakami, Y. Takemoto, T. Saiki, K. Miyamoto and S. Wada (2007) Spindles of an entomopoxvirus facilitate its infection of the host insect by disrupting the peritrophic membrane. J. Virol. 81: 4235-4243.

Morlais, I. and D. W. Severson (2001) Identification of a polymorphic mucin-like gene expressed in the midgut of the mosquito Aedes aegypti, using an integrated bulked segregant and differential display analysis. Genetics 158: 1125-1136.

Moskalyk, L. A., M. M. Oo and M. Jacobs-Lorena (1996) Peritrophic matrix proteins of Anopheles gambiae and Aedes aegypti. Insect Mol. Biol. 5: 261-268.

Okuda, K., A. de Souza Caroci, P. E. Ribolla, A. G. de Bianchi and A. T. Bijovsky (2002) Functional morphology of adult female Culex quinquefasciatus midgut during blood digestion. Tissue Cell. 34: 210-219.

Okuda, K., A. Caroci, P. Ribolla, O. Marinotti, A. G. de Bianchi and A. T. Bijovsky (2005) Morphological and enzymatic analysis of the midgut of Anopheles darlingi during blood digestion. J. Insect Physiol. 51: 769-776.

Pascoa, V., P. L. Oliveira, M. Dansa-Petretski, J. R. Silva, P. H. Alvarenga, M. Jacobs-Lorena and F. J. Lemos (2002) Aedes aegypti peritrophic matrix and its interaction with heme during blood digestion. Insect Biochem. Mol. Biol. 32: 517-523.

Perrone, J. B. and A. Spielman (1988) Time and site of assembly of the peritrophic membrane of the mosquito Aedes aegypti. Cell Tissue Res. 252: 473-478.

Peters, W. (1992) Peritrophic membranes. In Zoophysiology (S. D. Bradshaw, W. Burggren, H. C. Heller, S. Ishii, H. Langer, G. Neuweiler and D. J. Randall, eds.). SpringerVerlag, Berlin, pp. 1-238.

Santos, J. N., R. M. Lanfredi and P. F. P. Pimenta (2006) The invasion of the midgut of the mosquito Culex (Culex) quinquefasciatus Say, 1823 by the helminth Litomosoides chagasfilhoi Moraes Neto, Lanfredi and De Souza, 1997. J. Invertebr. Pathol. 93: 1-10.

Secundino, N. F., I. Eger-Mangrich, E. M. Braga, M. M. Santoro and P. F. Pimenta (2005) Lutzomyia longipalpis peritrophic matrix: formation, structure, and chemical composition. J. Med. Entomol. 42: 928-938.

Shao, L., M. Devenport and M. Jacobs-Lorena (2001) The peritrophic matrix of hematophagous insects. Arch. Insect Biochem. Physiol. 47: 119-125.

Shao, L., M. Devenport, H. Fujioka, A. Ghosh and M. JacobsLorena (2005) Identification and characterization of a novel peritrophic matrix protein, Ae-Aper 50, and the microvillar membrane protein, AEG12, from the mosquito, Aedes aegypti. Insect Biochem. Mol. Biol. 35: 947-959.

Stamm, B., J. D'Haese and W. Peters (1978) SDS gel electrophoresis of proteins and glycoproteins from peritrophic membranes of some Diptera. J. Insect Physiol. 24: 1-8.

Staubli, W., T. A. Freyvogel and J. Suter (1966) Structural modifications of the endoplasmic reticulum of midgut epithelial cells of mosquitoes in relation to blood intake. J. Microsc. 5: 189-204.

Tellam, R. (1996) The peritrophic matrix. In Biology of the Insect Midgut (M. J. Lehane and P. F. Billingsley, eds.). Chapman and Hall, London, pp. 86-108.

Tellam, R. L., G. Wijffels and P. Willadsen (1999) Peritrophic matrix proteins. Insect Biochem. Mol. Biol. 29: 87-101.

Terra, W. R. (1990) Evolution of digestive systems of insects. Annu. Rev. Entomol. 35: 181-200.

Terra, W. R. (2001) The origin and functions of the insect peritrophic membrane and peritrophic gel. Arch. Insect Biochem. Physiol. 47: 47-61.

Villalon, J. M., A. Ghosh and M. Jacobs-Lorena (2003) The peritrophic matrix limits the rate of digestion in adult Anopheles stephensi and Aedes aegypti mosquitoes. J. Insect Physiol. 49: 891-895.

Wang, P. and R. R. Granados (2001) Molecular structure of the peritrophic membrane (PM): identification of potential PM target sites for insect control. Arch. Insect Biochem. Physiol. 47: 110-118.

Weaver, S. C. and T. W. Scott (1990) Peritrophic membrane formation and cellular turnover in the midgut of Culiseta melanura (Diptera: Culicidae). J. Med. Entomol. 27: 864-873.

Wijffels, G., S. Hughes, J. Gough, J. Allen, A. Don, K. Marshall, B. Kay and D. Kemp (1999) Peritrophins of adult dipteran ectoparasites and their evaluation as vaccine antigens. Int. J. Parasitol. 29: 1363-1377.

Zhuzhikov, D. P. (1964) Function of the peritrophic membrane in Musca domestica L. and Calliphora erythrocephala Meig. J. Insect Physiol. 10: 273-278.

Zimmermann, D. and W. Peters (1987) Fine structure and permeability of peritrophic membranes of Calliphora erythrocephala (Meigen) (Insecta: Diptera) after inhibition of chitin and protein synthesis. Comp. Biochem. Physiol. 86: 353-360. 